\title{
Variations of a $\mathrm{Y}$ chromosome repeated sequence across subspecies of Mus musculus
}

\author{
P. Boursot, \\ F. Bonhomme, \\ J. Catalan* and \\ K. Moriwakit
}

\author{
* Institut des Sciences de l'Evolution (C.N.R.S., \\ UA 327), Equipe Génome et Populations, Université \\ Montpellier II, 34060 Montpellier, France \\ $\div$ Department of Cytogenetics, National Institute of \\ Genetics, Yata 1-111, Mishima, Shizuoka 411, Japan
}

The complex species Mus musculus is widespread in Eurasia and consists of four parapatric genetical entities (subspecies) that have recently radiated. Two of them $(M$. $m$. domesticus and $M$. $m$. musculus) are known to interact through a narrow zone of hybridisation across which autosomal and mitochondrial exchanges are very limited and $Y$ chromosome exchange is absent. We extend here the study of this group by the genetical analysis of 22 Asian strains of various origins (China, Korea, Japan, Taiwan, Philippines and Indonesia). A survey of protein variation at ten polymorphic loci confirmed that these animals belong to either the subspecies $M$. $m$. musculus (northern type in Asia, ranging westwards to Eastern Europe) or to $M$. $m$. castaneus (southern Asian type) and revealed a certain degree of intergradation between the two taxa. Y chromosome variations were assessed in these strains using a Y specific DNA probe representing part of a small multigene family and also in four $M$. $m$. domesticus (the Western European house mouse) strains of various origins and one $M . m$. bactrianus (from Pakistan). Musculus and castaneus were identically monomorphic for one type of organisation of this $Y$ repeated family, while domesticus and bactrianus were very similar to each other, showing slightly different types of organisation. Introgression of a bactrianus $Y$ chromosome into the territory of castaneus was found in Indonesia. The present distribution of the $Y$ types among the four subspecies is not phylogenetically concordant with the known distributions of autosomal and mitochondrial variants. The possible role of reticulation to account for this is discussed. The repeated family is organised in a limited number of subfamilies that characterise each of our $Y$ types, indicating that a mechanism of concerted evolution underlies its recent evolution in Mus musculus.

\section{INTRODUCTION}

Molecular evolutionary genetics lies at the interface between the biology of populations and species and the evolution of molecules. As the different compartments of the genome do not have the same functions, modes of transmission, and mechanisms of molecular evolution, they can be affected differently by the actions of drift, selection and migration during the evolution of a species or a speciation event. The mosaic and reticulate picture of molecular evolution that seems to be emerging has been particularly well documented in mice where a wealth of data on different markers in different species is available (see Bonhomme, $1986 a, b$; Moriwaki, 1986 for recent reviews of the question). The four subspecies of the complex species Mus musculus which are the most recently diverged taxa of the group seem to have a particularly complex evolutionary history. They are thought to have radiated $1-3$ million years ago and are now parapatric (see fig. 1 for the names and geographical division of the four subspecies). Where they meet, they can hybridise, the best documented cases of secondary interactions being the hybrid zone between $M$. $m$. domesticus and $M . m$. musculus in Europe (Hunt and Selander, 1973; Boursot et al., 1984; Sage et al., 1986; Vanlerberghe et $a l ., 1988 a, b)$ and the Japanese population $(M$. $m$. molossinus). Mitochondrial DNA polymorphism (Yonekawa et al., 1986, 1988) and protein variation data presented in the companion paper (Bonhomme et al., 1989) have shown $M . m$. molossinus to be a complex admixture of $M . \mathrm{m}$. musculus and $M$. $m$. castaneus. There is increasing, evidence of a gene flow between bactrianus and domesticus and between bacirianus and castaneus (Miyashita et al., 1985; Suzuki et al., 1985) but the nature of these interactions is not yet known (fig. 1).

Studying the molecular evolution of the $Y$ chromosome in this context appears interesting for 


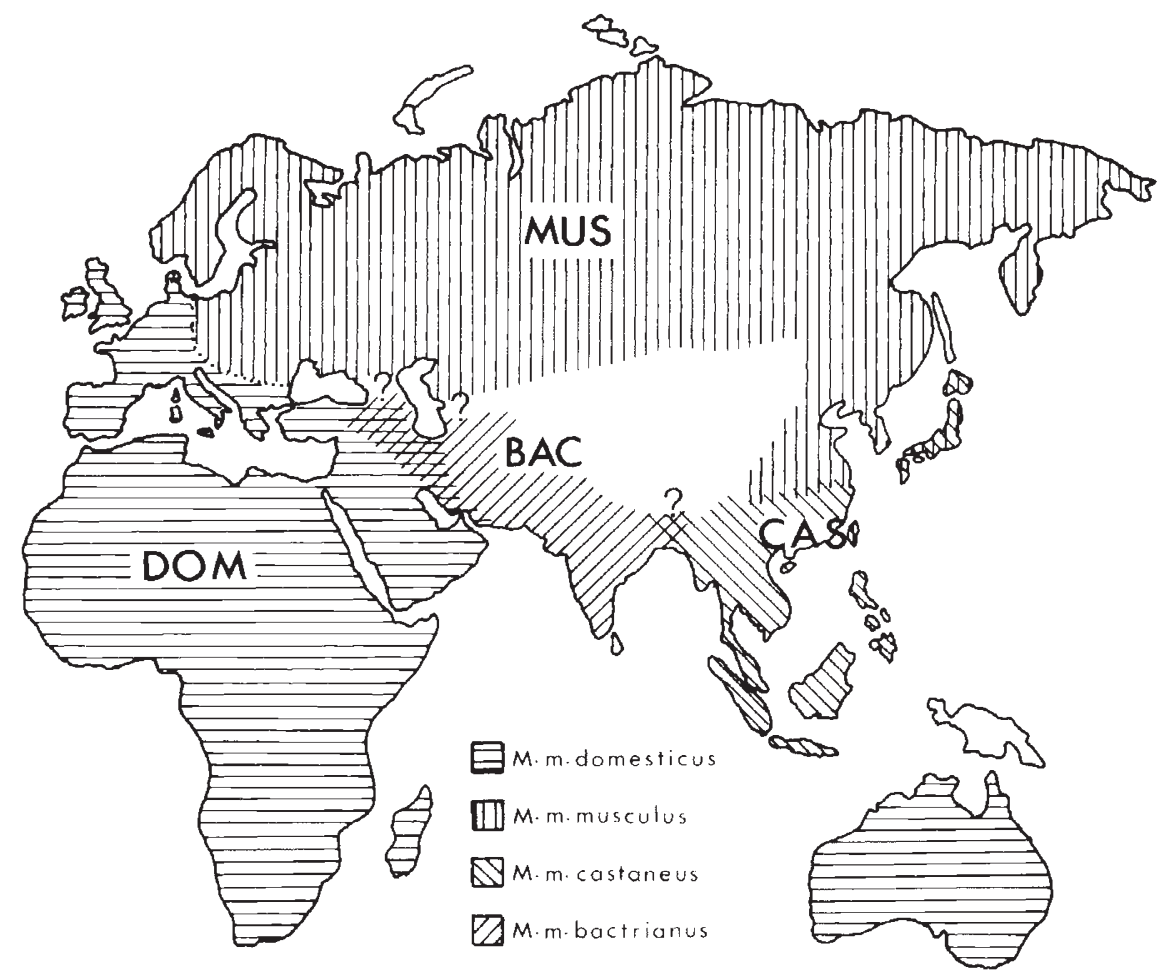

Figure 1 Geographic distribution of the four subspecies of Mus musculus (modified from Bonhomme, 1986b).

two main reasons. First from the viewpoint of genetics, the $Y$ chromosome plays an important role in sex determination, in combination with $\mathrm{X}$-linked and autosomal genes and is thus an important potential source of reproductive isolation between taxa. Second, from the viewpoint of molecular evolution the $\mathrm{Y}$ is peculiar in that it undergoes hardly any meiotic recombination. The consequences of this on the mode of evolution of the numerous repetitive sequences it bears are yet unexplored. In this paper we investigate these two aspects of the evolution of the $\mathrm{Y}$ chromosome in the four subspecies of the complex species Mus musculus using southern blot analyses of a battery of wild derived strains and a $Y$ specific DNA probe. The probe, $\mathrm{pY} 353 / \mathrm{B}$, is a $\mathrm{Y}$ specific sequence which detects a family of sequences that are repeated about 250 times along the $\mathrm{Y}$ chromosome (Bishop and Hatat, 1987). It also detects a testis specific transcript the function of which is not known (Bishop et al., 1987). pY353/B has been shown to discriminate the $\mathrm{Y}$ chromosomes of the two European subspecies $M$. m. domesticus and M. m. musculus (Bishop et al., 1985). Using this property, it was possible to show that there was a sharp transition from one $\mathrm{Y}$-type to the other across the hybrid zone between these two subspecies. It has been proposed that this absence of $\mathrm{Y}$ introgression was due to selection preserving differentiated coadapted sex determination systems in the two subspecies (Vanlerberghe et al., 1986).

In this paper we show that the musculus-type Y chromosome defined by RFLPs detected with the $\mathrm{pY} 353$ / B probe is present everywhere in China, Japan and South-East Asia, and that this probe thus fails to detect any $\mathrm{Y}$ differentiation between the subspecies $M$. m. musculus and $M$. m. castaneus which as we show are clearly distinguishable on the basis of protein polymorphism at ten polymorphic loci. Furthermore the bactrianus Y chromosome is found to be closely related to that of domesticus, as far as the organisation of this family of repeated sequences is concerned. The use of an extensive set of restriction enzymes shows that within the four subspecies a mechanism of concerted evolution has led to the formation of the different types of $\mathrm{Y}$ chromosomes revealed by pY353/B in the four subspecies. 


\section{MATERIALS AND METHODS}

\section{Animals}

A list of the animals studied is given in table 1 . Most of them belong to partly inbred laboratory stocks of wild origin. Twenty two of these strains are Asian mice, whose origins are shown on the map in fig. 2. They belong to either M. m. musculus, M. $m$. castaneus or Japanese mice often named M. m. molossinus). For comparison we included one strain of European M.m. musculus, four strains of $M$. $m$. domesticus of various origins and one individual of $M . \mathrm{m}$. bactrianus origin.

\section{Protein study}

Experimental protocols and the treatment of data by correspondence analysis were as described in the companion paper (Bonhomme et al.)

\section{DNA studies}

Genomic DNA was extracted from single animals. Soft organs (liver, spleen, and kidneys) were chopped in $10 \mathrm{ml}$ of 5 per cent citric acid, then homogenised by 5-10 strokes in a motor driven teflon homogeniser. After a centrifugation of $5 \mathrm{~min}$

Table 1 List of the samples studied.

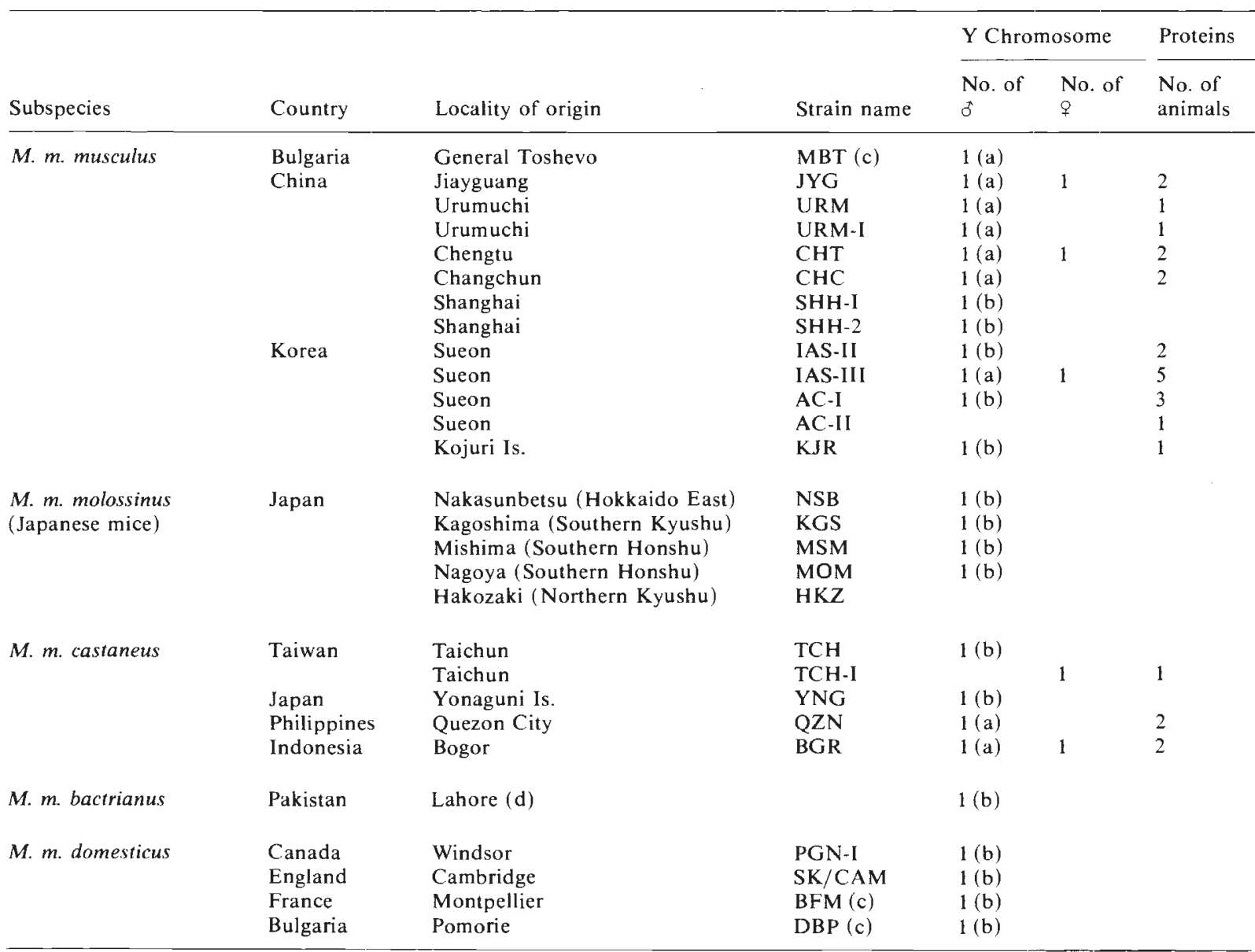

(a) Analysed with all enzymes (Eco RI, Hae III, Hind II, Hind III, Bgl II, Kpn I, Bam HI, Taq I, Hinf I, Alu I, Hpa I, Pvu II, Pst I).

(b) Analysed with Alu I, Hpa I, Pvu II, Pst I.

(c) Strains described in Potter (1986), maintained at the Institut des Sciences de l'Evolution, Montpellier, France. All other strains maintained at the National Institute of Genetics, Mishima, Japan.

(d) The individual studied is a male hybrid between a wild $M . m$. bactrianus male and a C57BI/6 female. 


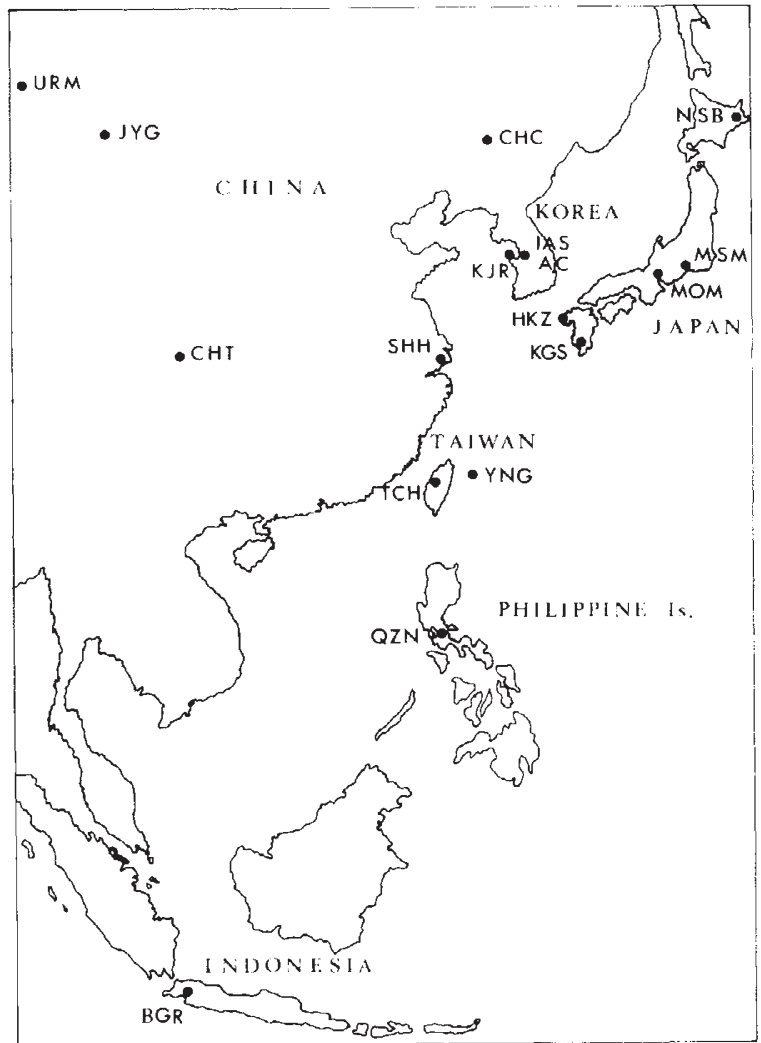

Figure 2 Geographical origin of the Asian samples analysed. The three letter codes correspond to the strain names of table 1.

at $2000 \mathrm{rpm}$., the pelleted nuclei were resuspended in $3 \mathrm{ml}$ of 5 per cent citric acid and loaded in a $15 \mathrm{ml}$ tube on top of a $7 \mathrm{ml}$ cushion of 30 per cent sucrose, 5 per cent citric acid. After centrifugation at $2500 \mathrm{rpm}$. for $8 \mathrm{~min}$ the pellet of nuclei was resuspended in $10 \mathrm{ml}$ of $\mathrm{RSB}(10 \mathrm{mM} \mathrm{NaCl}$, $25 \mathrm{mM}$ EDTA, $10 \mathrm{mM}$ Tris- $\mathrm{HCl} p \mathrm{H} \mathrm{7.5).} \mathrm{The}$ nuclei were pelleted again and resuspended in $5 \mathrm{ml}$ RSB. Proteinase $\mathrm{K}$ and SDS were added to final concentrations of $100 \mu \mathrm{g} / \mathrm{ml}$ and 1 per cent respectively. The mixture was incubated overnight at $37^{\circ} \mathrm{C}$, then made up to $0.2 \mathrm{M} \mathrm{NaCl}$ and incubated one hour at $37^{\circ} \mathrm{C}$ after adding RNAse to a final concentration of $50 \mu \mathrm{g} / \mathrm{ml}$. After phenol and chloroform extractions, the DNA was ethanol precipitated.

Restriction enzyme digestions were performed as recommended by the manufacturer (Takara). DNAs were electrophoresed in 0.6 or 1.5 per cent horizontal agarose gels and blotted onto nylon membranes (Hybond, Amersham) by capillary transfer by one of the following methods: (1) the gel was soaked 7 min in $0.3 \mathrm{~N} \mathrm{HCl}$, then two times $15 \mathrm{~min}$ in $0.5 \mathrm{M} \mathrm{NaOH}$ and two times $15 \mathrm{~min}$ in $1 \cdot 0 \mathrm{M}$ Tris- $\mathrm{HCl}, p \mathrm{H} \mathrm{7.5}$. After overnight transfer with distilled water the nylon membrane was exposed for $5 \mathrm{~min}$ to the UV light of a sterile cabinet. (2) After electrophoresis the gel was exposed $5 \mathrm{~min}$ to UV light on a transilluminator. Transfer was made directly with $0.4 \mathrm{~N} \mathrm{NaOH}$ overnight. After transfer the membrane was neutralised by incubation in $2 \times \mathrm{SSC}$.

Probe labeling with alpha- ${ }^{32} \mathrm{P}$ dCTP was made by the random priming method described by Feinberg and Vogelstein (1983). After hybridisation the membranes were washed under stringent conditions, at $68^{\circ} \mathrm{C}$ in $0.1 \times \mathrm{SSC}$.

\section{RESULTS}

\section{Protein variation}

In order to assess the taxonomic relationships of our samples and to better understand the genetic interactions between the two subspecies $M . m$. musculus and $M$. m. castaneus in Asia we studied protein polymorphism at 35 enzymatic loci.

Twenty five loci were identically monomorphic in all samples (Aat-2, Acp, Ada, Adh-1, Ak-1, $A k-2, A m y-1, C k-1$, Es-1, Es-3, Es-14, Gda, Gdc1, Glo-2, Gpd-1, Gpi-1, Id-2, Ldh-1, Ldh-2, Mod1, Mod-2, Mor-1, Mor-2, Pgd, Sdh-1). Table 2 gives the allele frequencies at the ten polymorphic loci in our sample. The factorial analysis of correspondences splits our sample in two blocks (see fig. 3) along axis one, which absorbs 52 per cent of the total inertia, a very high value for this type of analysis. One compact block contains the reference $M . m$. musculus and all samples from China and Korea. It represents what we could call the musculus pole of our sample. The second block represents the castaneus pole. It is less compact and comprises the southernmost localities (Taiwan, Philippines and Indonesia) plus the castaneus reference sample. The splitting along axis one is mostly explained by loci Sod-1 and Es-10 which, as can be seen in table 2 , possess alleles diagnostic for these two blocks. The spreading of the castaneus block along axis one results mostly from the modalities found at the Aat-1 and $\mathrm{Np}-1$ loci which put the Taiwan sample closer to the musculus pole with which it shares the alleles 100 and 85 respectively. The musculus reference sample lies away from the compact Chinese and Korean group because of its private $I d h-2^{125}$ allele (table 2). 
Table 2 Allele frequencies (in percentages) observed at 10 protein loci in our samples

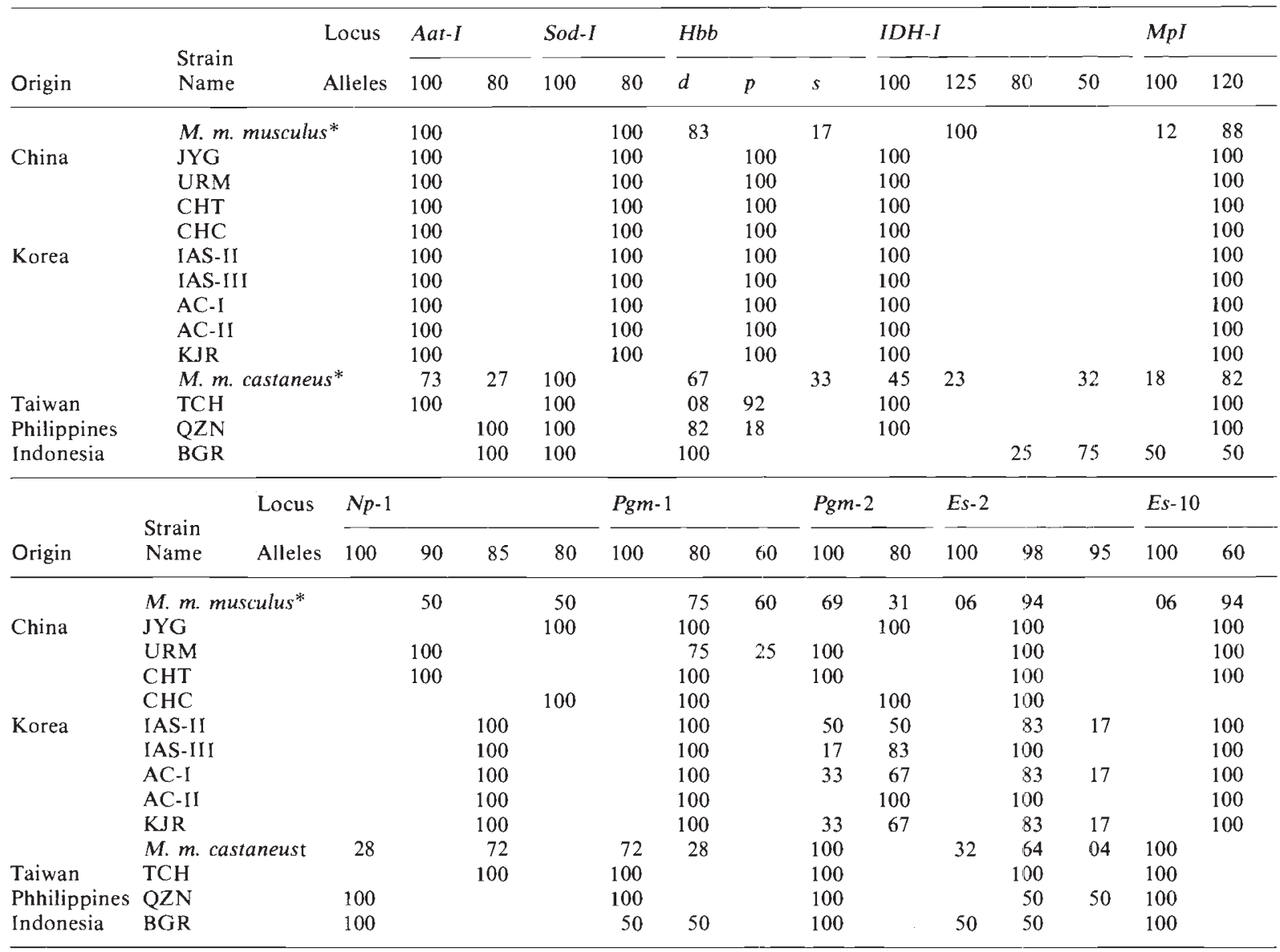

* Reference samples - Data are from Bonhomme et al. (1984).

\section{Y chromosome RFLP}

In order to assess $\mathrm{Y}$ chromosome differentiation in Mus musculus and possible exchanges between musculus and castaneus we surveyed our Asian sample for RFLP with the probe pY353/B, and compared the patterns to those of the other subspecies (domesticus and bactrianus).

The few female DNAs prepared (table 2) were tested with one restriction enzyme and did not hybridise with the probe (data not shown).

Most of the Asian male samples of M. m. musculus and M. m. castaneus were surveyed with 13 restriction enzymes (table 1). Three enzymes (EcoR I, Hae III and Hind II) did not reveal any difference between the strains (data not shown). The other ten enzymes (Alu I, Bam HI, Bgl II, Hind III, Hinf I, Hpa I, Kpn I, Pst I, Pvu II and
Taq I) produced two distinctive patterns, one with the strain from Bogor (Indonesia), and another found in all the other Asian strains (patterns shown in fig. 4). The patterns obtained with the first three enzymes and the most common ones obtained with the ten other enzymes were the same as those obtained with the European $M . m$. musculus strain (MBT from Bulgaria). The five strains of Japanese mice also displayed the same patterns.

Using four of the enzymes that discriminate between the Bogor strain and the other Asian strains (Alu I, Hpa I, Pvu II and Pst I) we compared Bogor to the two other M. musculus subspecies, $M$. $m$. bactrianus (one animal from Iran) and $M . m$. domesticus (four strains from England, Canada, France and Bulgaria). Although the patterns were very similar (fig. 4) small differences seen with Hpa I, Pvu II and Pst I showed the 


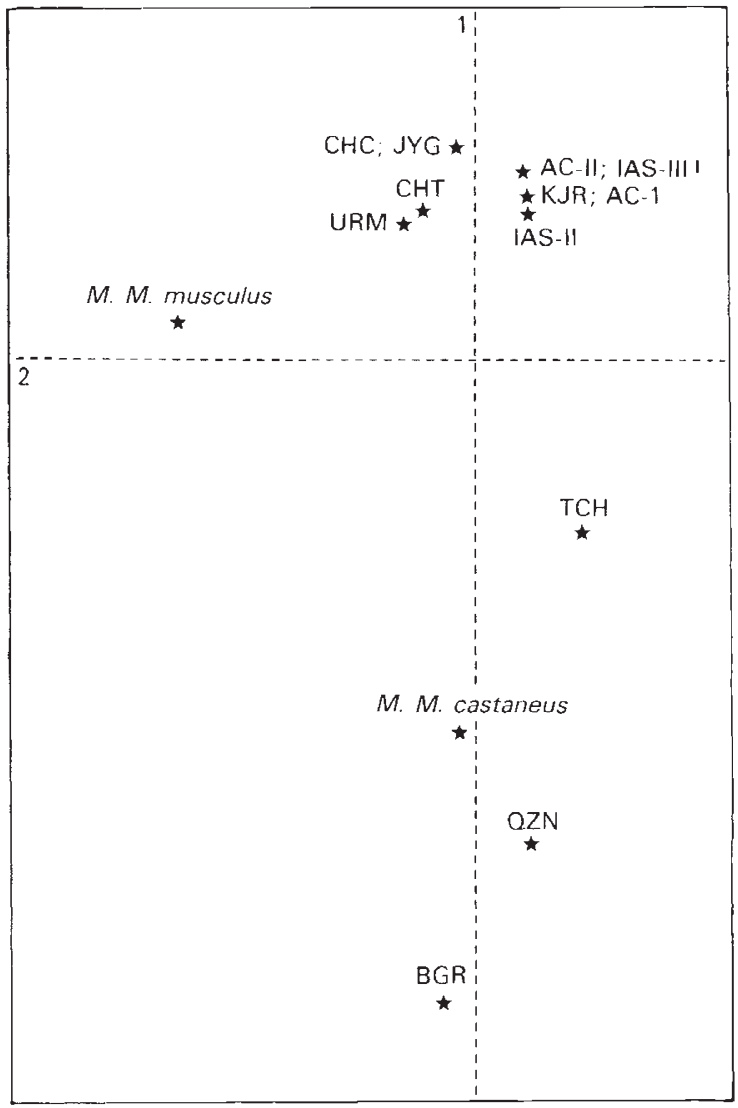

Figure 3 Factorial correspondence analysis based on the allelic composition of table 2 . We show here the projection of the sample-points (stars) in the plan defined by axis 1 (vertical) and 2 (horizontal), which absorb 52 and 18 per cent of the total inertia of the sample, respectively. Samples are identified by subspecies names or three letter codes as in tables 1 and 2 .

Bogor strain and bactrianus to be identical and different from the four domesticus which were undistinguishable (data not shown).

This study shows that differences in the organisation of the family of repeated sequences hybridising to $\mathrm{pY} 353 / \mathrm{B}$ define two major types of $Y$ chromosomes in the four $M$. musculus subspecies. One is common to $M$. m. musculus and $M$. $m$. castaneus, the other to $M$. $m$. bactrianus and $M$. m. domesticus. Small differences however could be detected between the last two subspecies. The reduced sample of bactrianus studied does not allow us to conclude that the variant type we found is fixed in this subspecies. However as this same type was found in Bogor we are inclined to think that it is not uncommon and reveals introgression of a bactrianus $\mathrm{Y}$ into Indonesian castaneus.

\section{DISCUSSION}

Our protein study reveals in Asia a north south differentiation which fits the subspecies classification, with $M$. m. musculus in the north (our Chinese and Korean samples) and $M$. $m$. castaneus in the south (Taiwan, Philippines and Indonesia). However the way these subspecies interact in nature is still poorly understood as the zone of contact has not been properly sampled. According to the mitochondrial DNA polymorphism data of Yonekawa et al. (1988) it lies between Chengtu (musculus mtDNA) and Kunming (castaneus mtDNA), and extends eastwards to reach Shanghai where these authors found both mtDNA types. The two subspecies can hybridise very well in the laboratory and the natural mouse population in Japan is a mixture of the two subspecies, as was shown by mtDNA studies (Yonekawa et al., 1988) and confirmed by a protein polymorphism survey presented in the companion paper (Bonhomme et al.). It is thus probable that the two subspecies hybridise where they meet in China. Our present protein data suggest that a certain degree of genetic intergradation between the two subspecies exists in Asia. This is particularly clear for our Taiwanese sample which, although clearly mostly of castaneus origin, has some characterisctic of the Chinese and Korean musculus (for instance the distribution of alleles $A a t-\mathrm{I}^{100}, H b b^{p}$ and $\mathrm{Np}-\mathrm{I}^{85}$ shown in table 2). Such a north-south differentiation with an apparent transition around Shanghai and Taiwan was also observed in an extensive survey of the $H b b$ locus in Asia by Miyashita et al. (1985), and for the non-transcribed ribosomal DNA spacers by Suzuki et al. (1985).

Our Y chromosome data contrast with these results since no $\mathrm{Y}$ differentiation could be detected between the two East-Asian subspecies with probe pY353/B using 13 restriction enzymes. As far as this repeated sequence is concerned, there seems to be only one Y chromosome type all over China, South-East Asia and Japan. The only variant we observed was in Bogor, and it probably results from an admixture of bactrianus into castaneus. Haploid non recombinant markers are good markers of genetic contamination events and mitochondrial DNA analysis of Asian mice have already pointed to the occurrence of bactrianus mtDNA haplotypes in Japan (Shikoku Island), China (Kunming) and Malaysia (Kota Kinabalu) and of domesticus haplotypes in Japan (Kyushu and Ogasawara Islands) and China (Beijung) (Yonekawa et al., 1988). Such sporadic occurrences of foreign genes are most probably due to 

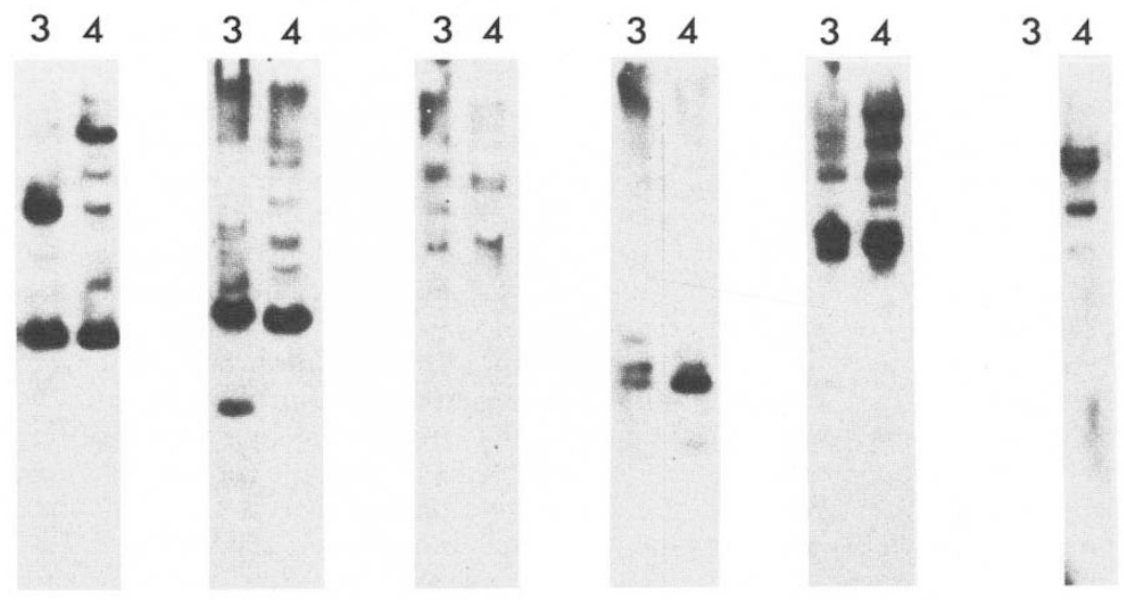

\section{BamHI Bgl II Hind III HinfI Kpn I Taq I}

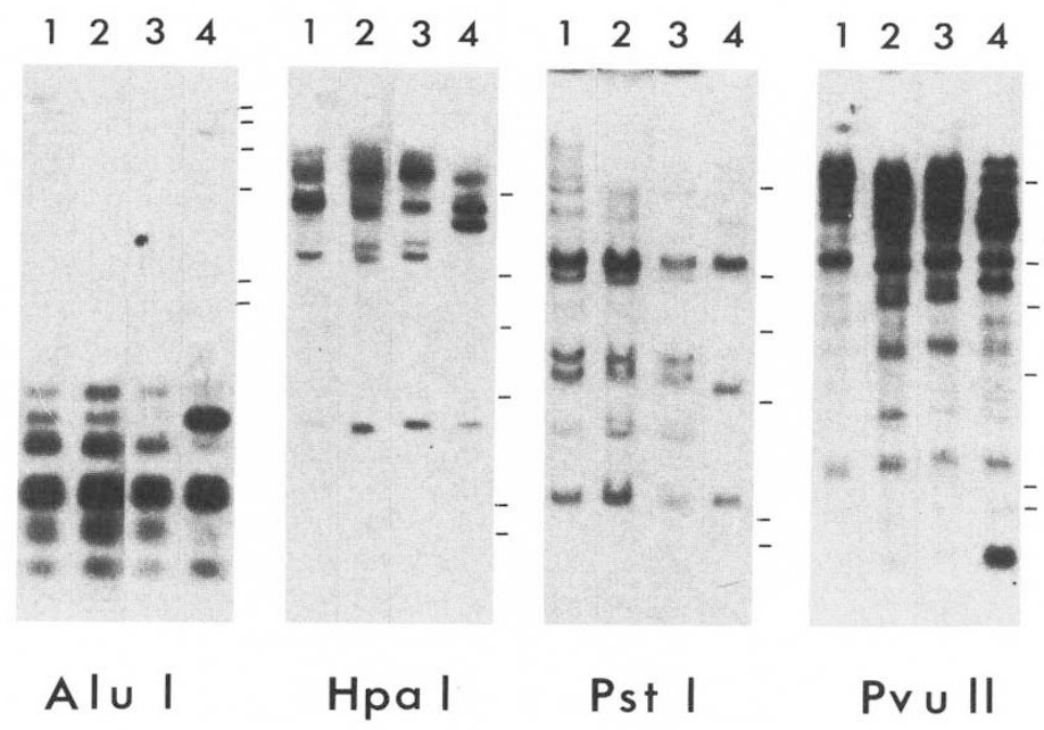

Figure 4 Restriction patterns observed for several enzymes after hybridisation with pY $353 / \mathrm{B} .1=M$. $m$. domesticus; $2=M$. $m$. bactrianus; $3=$ Bogor strain (BGR); $4=M$. m. musculus $+M$. m. castaneus. The scales on the right of the gels indicate the migration distances of the fragments of lambda phage DNA cut by Hind III (from top to bottom 23130, 9416, 6682, 4361, 2322 and 2027 basepairs).

secondary imigration linked to human activity. Although the possibility that they result from the persistence of an ancestral polymorphism could be ruled out by a phylogenetic analysis in the case of mtDNA (Yonekawa et al., 1988) this is not possible with our $\mathrm{Y}$ data as no intrasubspecies variation was detected, either in our Asian study or in extensive surveys of European populations (Bishop et al., 1985, Vanlerberghe et al., 1986).
However this very lack of variation among subspecies makes the contamination hypotheses more acceptable in the case of our Bogor sample.

Interestingly our study shows that only two main type of organisation of this Y repeated family have been retained during the evolutionary process leading to the four present subspecies of $M$. musculus which from the viewpoint of nuclear encoded proteins or mtDNA form four clearly distinct 
entities (Bonhomme et al., 1984; Yonekawa et al., 1981). The reasons why musculus and castaneus retained the same $\mathrm{Y}$ while the domesticus and bactrianus Ys appear to be closely related are not clear since the information from other genetic markers do not provide any clear evidence in favour of such a phylogenetic partitioning of the subspecies. When looking at the phylogenetic distribution of the variants for several individual nuclear markers among the subspecies, one finds many incongrueties in the cladistic information obtained for the different systems (see Bonhomme, $1986 a, b$; Moriwaki, 1986 for reviews of the question). It is probably the rapidity of the radiation from the common ancestor that allowed such extreme mosaicism to prevail among the four present groups. However, because several examples of it are already well documented, reticulation must be considered as a possible explanation of the taxonomic distribution of our $\mathrm{Y}$ variants. A complete takeover of domesticus mtDNA in the Scandinavian M. m. musculus populations occurred during the colonisation of this area by mice (Ferris et al., 1983; Gyllensten and Wilson, 1987; Vanlerberghe et al., 1988b). The Japanese mouse population is a mixture of $M . m$. musculus and $M . m$. castaneus genomes that results from multiple migration waves and consecutive intermixing (Yonekawa et al., 1988; Bonhomme et al., 1989. There is increasing evidence that $t$-haplotypes have leaped over subspecies boundaries (Silver et al., 1987; Delarbre et al., 1988).

The role $\mathrm{Y}$ chromosome differentiation plays in the reproductive isolation between subspecies can be addressed by asking whether there is a link between the way any pair of subspecies interact in natura and which of the two main $\mathrm{Y}$ types each of them bears. M. m. domesticus and M. m. musculus which have different Ys (as far as revealed by $\mathrm{pY} 353 / \mathrm{B}$ ) form a narrow hybrid zone across which autosomal and mitochondrial exchanges are restricted (see Vanlerberghe et al., 1988 $a$ and references therein) and Y exchanges are absent (Vanlerberghe et al., 1986) while M. m. musculus and $M$. $m$. castaneus which have undistinguishable Ys have extensively hybridised in Japan, as mentioned earlier. An extension of this "rule" would predict that hybridisation and genetic introgression should be more extensive between bactrianus and domesticus than between bactrianus and castaneus. Presently available data however, although scarce, do not provide evidence for this. In the case of mitochondrial DNA, as we mentioned before, bactrianus introgression occurs in several places in Asia and is thus not that uncommon. Data on the distribution over Eurasia of $\mathrm{Hbb}$ alleles (Miyashita et al., 1985) or rDNA haplotypes (Suzuki et al., 1985) also suggest a certain intergradation between bactrianus and castaneus.

The molecular organisation on the $\mathrm{Y}$ chromosome of the family of sequences defined by the py353/B sequence is poorly known. The fact that with each restriction enzyme only a limited number of major bands are obtained means that it is structured in a few different subfamilies. When comparing the different types found (fig. 4) one can see that for each enzyme they differ by one or more of these major bands. This is an indication that subfamilies evolve in a concerted way (see for instance Dover, 1982 for a review of this concept), different copies being more similar in sequence within a lineage than between different lineages. Unequal crossing over is a possible mechanism leading to concerted evolution (Dover, 1982). It would have to be between sister chromatids in the case of our $\mathrm{Y}$ sequence because there is no trace of this sequence on the $\mathrm{X}$ chromosome and recombination with the $X$ is anyway very limited. Retroposition is another possible mechanism since it has been shown that this sequence is transcribed in the testis (Bishop and Hatat, 1987). Nevertheless, to account for the present distribution of subfamily organisation found in $M$. musculus and its surprising homogeneity over such a large range and across subspecies we have to hypothetise that the spreading or disappearance of subfamilies was limited to a small number of sudden bursts of homogenisation before the radiation of the extent populations of mice.

Nishioka and Lamothe (1987) have studied the phylogenetic distribution of another family of repeated $Y$ specific sequences and shown that the male specific accumulation of these sequences was a recent event in the history of the Genus Mus. Similarly we have evidence (B. Dod, personal communication) that the amplification of the sequence family revealed by $\mathrm{pY} 353 / \mathrm{B}$ is recent as it is observed only in the four most recently diverged species of the Genus (including Mus musculus). This gives us an idea of the time scale of the evolution of this sequence, with an amplification event 1-3 million years ago and at least three reorganisations since the radiation of Mus musculus during the last million years or so.

Acknowledgements We thank Dr B. Dod for helpful comments on the manuscript and Dr C. Bishop for providing the DNA probe. P.B. was supported by a post-doctoral fellowship from the Japan Society for the Promotion of Science. The research was partly supported by the "Association pour la Recherche sur le Cancer” (Grant No. 6298). 


\section{REFERENCES}

BISHOP, C. E., BOURSOT, P., BARON, B., BONHOMME, F. AND HATAT, D. 1985. Most classical Mus musculus domesticus laboratory strains carry a Mus musculus musculus $\mathrm{Y}$ chromosome, Nature (London), 315, 70-72.

BISHOP, C. E. AND HATAT, D 1987. Molecular cloning and sequence analysis of a mouse $\mathrm{Y}$ chromosome RNA transcript expressed in the testis. Nucleic Acids Res., 15, (7), 2959-2969.

BISHOP, C. E., ROBERTS, C., MICHOT, J.-L., NAGAMINE, C., WINKING, H., GUENET, J.-L. AND WEITH, A. 1987. The use of specific DNA probes to analyse the $S x r$ mutation in the mouse. In Goodfellow, P. N., Craig, I. W., Smith, J. C. and Wolfe, J. (eds) The Mammalian Y Chromosome: Molecular Search for the Sex-Determining Factor, The Company of Biologists Limited, Cambridge, pp. 167-175.

BONHOMME, F. 1986a. Evolutionary relationships in the Genus Mus, In Potter, M., Nadeau, J. H. and Cancro, M. P. (eds) The Wild Mouse in Immunology, Springer-Verlag Publisher, pp. 19-34.

BONHOMME, F. $1986 b$. Molecules, populations and species evolution in the Genus Mus (Mammalia: Rodentia), In Iwatsuki, K., Raven, P. H. and Bock, W. (eds) Modern Aspects of the Species, University of Tokyo Press, pp. 125143.

BONHOMME, F., CATALAN, J., BRITTON-DAVIDIAN, J., CHAPMAN, V. M., MORIWAKI, K., NEVO, E. AND THALER, L. 1984. Biochemical diversity and evolution in the Genus Mus. Biochem. Genet., 22, 275-303.

BONHOMME, F., MIYASHITA, N., BOURSOT, P., CATALAN, J. AND MORIWAKI, K. 1989. Genetical variation and polyphyletic origin in Japanese Mus musculus. Heredity, 63, 299-308.

BOURSOT, P., BONHOMME, F., BRITTON-DAVIDIAN, J., CATALAN, J., YONEKAWA, H., ORSINI, P., GERASIMOV, S. AND THALER, L. 1984. Introgression différentielle des génomes nucléaires et mitochondriaux chez deux semiespèces européennes de souris. C. R. Acad. SCi., Ser. III, 299, 691-693.

DELARBRE, C., KASHI, Y., BOURSOT, P., BECKMAN, J. S., KOURILSKY, P., BONHOMME, F. AND GACHELIN, G. 1988. Phylogenetic distribution in the genus Mus of t-complex specific DNA and protein markers: inferences on the origin of t-haplotypes. Mol. Biol. Evol., 5, (2), 120-133.

Dover, G. 1982. Molecular drive: a cohesive mode of species evolution. Nature, 299, 111-117.

FEINBERG, A. P. ANI VOGELSTEIN, B. 1983. A technique for radiolabelling DNA restriction endonuclease fragments to high specific activity. Anal. Biochem., 132, 6-13.

FERRIS, S. D., SAGE, R. D., HUANG, C. M., NIELSEN, J. T., RITTE, U. AND WILSON, A. C. 1983. Flow of mitochondrial DNA across a species boundary. Proc. Natl Acad. Sci. USA, 80, 2290-2294.

GYLLENSTEN, U. AND WILSON, A. C. 1987. Interspecific mitochond rial DNA transfer and the colonization of Scandinavia by mice. Genet. Res. Camb., 49, 25-29.

HUNT, W. G. AND SELANDER, R. K. 1973. Biochemical genetics of hybridisation in European house mouse. Heredity, 31, 11-33.

MIYASHITA, N., MORIWAKI, K., MINEZAWA, M., YONEKAWA, H., BONHOMME, F., MIGITA, S., YU, Z.C., LU, D.-Y., CHO, W. S. AND TOHARI, M. 1985. Allelic constitution of the hemoglobin beta chain in wild populations of the house mouse, Mus musculus. Biochem. Genet., 23, (11-12), 975986.
MORIWAKI, K. 1986. Genetic features of major geographic isolates of Mus musculus, In Potter, M., Nadeau, J. H. and Cancro, M. P. (eds) The Wild Mouse in Immunology, Springer-Verlag Publisher, pp. 55-67.

NISHIOKA, Y. AND LAMOTHE, E. 1987. Evolution of a mouse $\mathrm{Y}$ chromosomal sequence flanked by highly repetitive elements. Genome, 29, 380-383.

POTTER, M. 1986. Listing of stocks and strains of mice in the genus Mus derived from the feral state, In Potter, M., Nadeau, J. H. and Cancro, M. P. (eds) The Wild Mouse in Immunology, Springer-Verlag Publisher, pp. 373-395.

SAGE, R. D., WhITNEY, J. B. AND WILSON, A. C. 1986. Genetical analysis of a hybrid zone between domesticus and musculus mice (Mus musculus complex): hemoglobin polymorphisms, In Potter, M., Nadeau, J. H. and Cancro, M. P. (eds) The Wild Mouse in Immunology, Springer-Verlag Publisher, pp. 75-85.

SILVER, L. M., HAMMER, M., FOX, H., GARRELS, J., BUCAN, M., HERRMANN, B., FRISCHAUF, A.-M., LEHRACH, H., WINKING, H., FIGUEROA, F. AND KLEIN, J. 1987. Molecular evidence for the rapid propagation of mouse $t$ haplotypes from a single, recent, ancestral chromosome. Mol. Biol. Evol. 4, (5), 473-482.

SUZUKI, H., MIYASHITA, N., MORIWAKI, K., KOMINAMI, R., MURAMATSU, M., KANEHISA, T., BONHOMME, F., PETRAS, M. L., YU, Z.C. AND LU, D.-Y. 1985. Evolutionary implication of heterogeneity of nontranscribed spacer region of ribosomal DNA repeating units in various subspecies of Mus musculus. Mol. Biol. Evol., 3, 126-137.

VANLFRBERGHE, F., DOD, B., BOURSOT, P., BELLIS, M. AND BONHOMME, F. 1986. Absence of Y chromosome introgression across the hybrid zone between Mus musculus domesticus and Mus musculus musculus. Genet. Res. Camb., 48, 191-297.

VANLERBERGHE, F., BOURSOT, P., CATALAN, J., GERASIMOV, S., BONHOMME, F., BOTEV, A. AND THALER, L. 1988a. Analyse génétique de la zone d'hybridation entre les deux sous-espèces de souris Mus musculus domesticus et Mus musculus musculus en Bulgarie. Genome, 30, 427-437.

VANLERBERGHE, F., BOURSOT, P., NIELSEN, J. T. AND BON HOMME, F. 1988b. A steep cline for mitochondrial DNA in Danish mice. Genet. Res. Camb., 52, 185-193.

YONEKAWA, H., MORIWAKI, K., GOTOH, O., HAYASHI, J.-1., WATANABE, J., MIYASHITA, N., PETRAS, M. L. AND TAGASHIRA, Y. 1981. Evolutionary relationships among five subspecies of Mus musculus based on restriction enzyme cleavage patterns of mitochondrial DNA Genetics, 98, 801-816.

YONEKAWA, H., GOTOH, O., TAGASHIRA, Y., MATSUSHIMA, Y., SHI, L.-1., CHO, W. S., MIYASHITA, N. AND MORIWAKI, K. 1986. A hybrid origin of Japarese mice "Mus musculus molossinus", In Potter, M., Nadeau, J. H. and Cancro, M. P. (eds) The Wild Mouse in Immunology, SpringerVerlag, Publisher, pp. 62-67.

YONEKAWA, H., MORIWAKI, K., GOTOH, O., MIYASHITA, N., MATSUSHIMA, Y., SHI, L., CHO, W. S., ZHEN, X.-L. AND TAGASHIRA, Y. 1988. Hybrid origin of Japanese mice " $M u s$ musculus molossinus": evidence from restriction analysis of mitochondrial DNA. Mol. Biol. Evol., 5 (1), 63-78. 